\title{
AVALIAÇÃO DO PROCESSO DE LOGÍSTICA REVERSA EM UMA EMPRESA FARMACÊUTICA
}

\author{
Amanda Ribeiro Castro \\ Universidade Presbiteriana Mackenzie \\ Rua da Consolação, 930. Consolação, São Paulo \\ amandaribeirocastro@outlook.com \\ Carolina Assalin \\ Universidade Presbiteriana Mackenzie Rua da Consolação, 930. Consolação, São Paulo \\ carol_massalin@hotmail.com \\ Flavia Beneduce \\ Universidade Presbiteriana Mackenzie \\ Rua da Consolação, 930. Consolação, São Paulo \\ flabeneduce@hotmail.com \\ Rachel Evangelista \\ Universidade Presbiteriana Mackenzie \\ Rua da Consolação, 930. Consolação, São Paulo \\ rachel.hevangelista@gmail.com \\ Max Filipe Silva Gonçalves \\ Universidade Presbiteriana Mackenzie \\ Rua da Consolação, 930. Consolação, São Paulo \\ max.goncalves@mackenzie.br
}

\begin{abstract}
RESUMO
Este artigo teve como objetivo analisar o fluxo do processo de devolução de materiais farmacêuticos em uma empresa do segmento e identificar oportunidades de melhorias. Foram avaliados quais os motivos mais relevantes das devoluções de produtos por parte dos clientes, principais gargalos no processo, seus impactos para a companhia e possíveis ganhos. O trabalho foi desenvolvido no setor de devolução de uma indústria do ramo farmacêutico, abordando o processo de devolução no ato da entrega ao cliente. Foram identificados os motivos pelos quais os itens são devolvidos, as oportunidades de melhorias, os ganhos com planos de ação e as dificuldades do processo. Os objetivos propostos para o trabalho foram alcançados, sendo possível observar o fluxo de retorno dos itens da empresa pesquisada assim como os principais motivos.
\end{abstract}

Palavra-chave: logística reversa; resíduos sólidos; devolução; coleta.

\begin{abstract}
This article aimed to analyze the process of return of pharmaceutical materials in a company of the segment and identify opportunities for improvement. The most relevant credits from product returns by customers, major bottlenecks in the process, their impacts on a company and eventual gains were earned. The work was developed in the return sector of a pharmaceutical
\end{abstract}


industry, addressing the return process upon delivery to the customer. This case is returned, the chances of increasing, the stock gains and the difficulties of the process. The proposed objectives for the work were achieved, being possible to observe the return of the items of the researched company as the main reasons.

Keywords: reverse logistic; solid waste; devolution; collect.

\section{Como Citar:}

CASTRO, Amanda Ribeiro; ASSALIN, Carolina. BENEDUCE, Flavia. EVANGELISTA, Rachel. GONÇALVES, Max Filipe Silva. Avaliação do processo de logística reversa em uma empresa farmacêutica. In: SIMPÓSIO DE PESQUISA OPERACIONAL E LOGÍSTICA DA MARINHA, 19., 2019, Rio de Janeiro, RJ. Anais [...]. Rio de Janeiro: Centro de Análises de Sistemas Navais, 2019.

\section{INTRODUÇÃO}

Os resíduos sólidos gerados pelas indústrias em geral têm grande impacto no Meio Ambiente e, devido ao excesso de desperdício e da gravidade das consequências de materiais descartados de forma inadequada, tornou-se imprescindível a criação de políticas e processos que garantam o descarte correto e sustentável de produtos acabados ou não. A Lei 12.305/2010, Política Nacional dos Resíduos Sólidos - PNRS, preconiza instruções para o descarte adequado de resíduos sólidos e líquidos. Importante ressaltar que alguns tipos de resíduos já possuem legislação específica, como o hospitalar e radioativo por exemplo, que são regulados pela Anvisa e CNEN respectivamente. A Logística Reversa - LR, é um instrumento de desenvolvimento econômico e social prevista na própria PNRS. É composta de ações e métodos que possibilitam a destinação final correta de resíduos sólidos, reaproveitamento ou coleta dos mesmos, de forma que o meio ambiente não seja prejudicado (SINIR, 2010). Porém, a Logística Reversa é apenas o começo da responsabilidade do pósconsumo, pois existem outros meios como melhorias de produtos e embalagens através do ecodesign, ou utilização de materiais que já passaram por processos de reciclagem e reutilização (CETESB-SP, 2015). Dentre os itens mais importantes da PNRS, destaca-se o acordo setorial, que consiste em formalizar a responsabilidade ambiental entre o poder público e fabricantes, importadores, distribuidores ou comerciantes (MINISTÉRIO DO MEIO AMBIENTE, 2010). Neste sentido, considerando que a logística reversa se subdivide em duas grandes áreas, a de pós-venda e de pós consumo, o foco desta pesquisa é estudar o retorno de itens do pós-venda. Assim, este trabalho tem como principal objetivo analisar o fluxo do processo de devolução de materiais farmacêuticos em uma empresa do segmento e identificar oportunidades de melhorias. Quanto aos objetivos específicos, serão avaliados quais os motivos mais relevantes das devoluções de produtos por parte dos clientes, principais gargalos no processo, seus impactos para a companhia e possíveis ganhos. $\mathrm{O}$ trabalho foi desenvolvido no setor de devolução de uma indústria do ramo farmacêutico, abordando o processo de devolução no ato da entrega ao cliente. Foram identificados os motivos pelos quais os itens são devolvidos, as oportunidades de melhorias, os ganhos com planos de ação e as dificuldades do processo. Segundo Christopher (1999), a decisão de gerenciar os fluxos reversos amplia ainda mais as oportunidades de acréscimo de valor de diferentes naturezas que a atividade logística pode agregar ao bem. Políticas governamentais, vantagens competitivas, mudanças tecnológicas, economia de energia e o mercado são forças que pressionam as empresas a considerarem os fluxos reversos no planejamento estratégico (DORNIER, 2000). O cenário atual de alta competitividade entre as companhias e da 
sociedade atrelados a preocupação constante da empresa quanto aos desperdícios relacionados a produtos e serviços, gerou o interesse no estudo do processo de devolução e a busca por oportunidades de desenvolvimento e aumento da lucratividade da empresa. Este trabalho é importante para apresentar uma possibilidade de avaliação de processos internos para compreender os motivos de LR pós venda.

\section{REFERENCIAL TEÓRICO}

Os novos padrões de competitividade de serviços ao cliente e as preocupações com a imagem corporativa tem incentivado cada vez mais a criação de canais reversos de distribuição que solucionem o problema da quantidade de produtos descartados no meio ambiente. Gomes e Ribeiro (2004) afirmam que a Logística Reversa - LR visa a eficiente execução da recuperação de produtos. Tem como propósitos a redução, a disposição e o gerenciamento de resíduos tóxicos e não tóxicos. O conceito de logística reversa (LR) é abordado por diversos autores no decorrer dos anos e, mesmo que seja tratado de maneiras diferentes, convergem para o mesmo sentido. Embora o conceito de logística reversa esteja presente há muito tempo, é difícil datar o surgimento deste termo com precisão (DE BRITO e DEKKER, 2002). O seu conceito é relativamente novo quando observado sob ponto de vista acadêmico, o seu surgimento na literatura ocorreu nos anos 70, mas mesmo assim bastante incorporado às questões de reciclagem de resíduos sólidos (DE BRITO, 2003). Para Ballou (2001), embora seja fácil pensar em logística como o gerenciamento do fluxo de produtos dos pontos de aquisição até os clientes, para muitas empresas há um canal logístico reverso que deve ser gerenciado também. A vida de um produto, do ponto de vista logístico, não termina com a sua entrega ao cliente. Os produtos tornam-se obsoletos, danificam-se ou estragam e são levados para seus pontos de origem para conserto ou descarte. Pode-se definir então logística reversa, conforme Rogers \& Tibbenlembke (1999), como o processo de planejamento, implementação e controle do fluxo de matérias-primas, estoque em processamento e produtos acabados (e seu fluxo de informação) do ponto de consumo até o ponto de origem, com o objetivo de recuperar valor ou realizar um descarte adequado. A logística reversa pode ser dividida em duas áreas de atuação: logística reversa de pós-venda e logística reversa pós-consumo. A primeira, o caso deste artigo, pode ser entendida como a área da logística reversa que trata do planejamento, do controle e da destinação dos bens sem uso ou com pouco uso, que retornam à cadeia de distribuição por diversos motivos: devoluções por problemas de garantia, avarias no transporte, excesso de estoques, prazo de validade expirado, entre outros. Já a logística reversa pós-consumo pode ser vista como a área da logística reversa que trata dos bens no final de sua vida útil, dos bens usados com possibilidade de reutilização e os resíduos industriais. Um processo de logística reversa de pós-venda bem gerenciado nas empresas constitui uma fonte de vantagem competitiva através da diferenciação no atendimento, que agrega valor perceptível aos clientes e, em longo prazo, os fideliza. Segundo Lacerda (2003), o fluxo reverso de produtos de pós-venda também pode ser usado, por exemplo, para manter os estoques reduzidos, diminuindo o risco com a manutenção de itens de baixo giro. $\mathrm{O}$ fabricante é responsabilizado pelo produto até o final de sua vida útil. Logo, a logística reversa está ganhando importância nas operações das empresas (BOWERSOX; CLOSS; HELFERICH, 1986), quer seja devido à recalls efetuados pela própria empresa, responsabilidade pelo correto descarte de produtos perigosos após seu uso, produtos defeituosos e desenvolvidos para troca, vencimento do prazo de validade dos produtos ou desistência por parte dos consumidores. Lacerda (2003) destaca três causas básicas: questões ambientais, diferenciação por serviço e redução de custo. Girando em torno 
desses três pilares, a empresa pode unir a eficiência de entregar um produto que satisfaça o seu cliente com sustentabilidade, âmbito mais almejado pelas organizações e ainda assim, permanecer competitiva. O descarte no ramo farmacêutico é de responsabilidade do estabelecimento gerador. Entre a instituição geradora (indústria farmacêutica) e o cliente final há, na maioria das vezes, o estabelecimento de varejo, ou seja, a farmácia. E, como em farmácias existem profissionais que respondem tecnicamente e detém conhecimento necessário, segundo o Conselho Regional de Farmácia de São Paulo, cabe a ele o gerenciamento da devolução. O profissional tem a responsabilidade de instruir o cidadão consumidor a não descartar medicamentos vencidos em lixos comuns, tampouco em esgotos. (CRFSP, 2012). Os resíduos provindos da indústria farmacêutica são chamados de RSS (Resíduos do Serviço de Saúde). Este é classificado pela RDC ANVISA n ${ }^{\circ}$ 306/04 e Resolução CONAMA n³58/05 em 5 grupos (ANVISA, 2006). O grupo A são agentes biológicos, ou seja, que são suscetíveis à risco de infecções, o B são aqueles que contém substâncias que podem causar danos ao meio ambiente ou saúde pública por terem características como inflamabilidade, toxicidade ou corrosividade, como medicamentos e reagentes químicos, o C são materiais radionucleares fora de especificação pré determinada, o grupo D são alimentos ou materiais inofensivos e por fim, o grupo E, que são materiais perfurantes ou cortantes. Assim, a partir da lista de grupos, pode-se concluir que o presente trabalho lidará com materiais que se encaixam no grupo B.

\section{METODOLOGIA}

A metodologia utilizada na elaboração deste trabalho pode ser classificada como uma pesquisa científica de natureza básica, segundo a forma de abordagem ao problema, mista (qualitativas e quantitativas), do ponto de vista dos objetivos, a pesquisa exploratória e utilizando-se de pesquisa bibliográfica, além do estudo de caso quanto aos procedimentos técnicos. A pesquisa classifica-se como natureza básica que possui como objetivo gerar conhecimentos novos para avanço da ciência sem aplicação prevista. Envolve verdades e interesses locais (GIL, 1994). Quanto à abordagem, pode-se dizer que possui enfoque misto, já que além de quantitativo, que é dada quando informações são transformadas em números e então comparadas e analisadas, também qualitativo, pois há utilização do enfoque indutivo na análise dos resultados dos diversos cenários propostos (SILVA e MENEZES, 2005). Com relação aos objetivos, a pesquisa pode ser classificada como exploratória, objetiva proporcionar maior familiaridade com um problema. (GIL, 1994). Quanto ao procedimento técnico, enquadra-se como pesquisa bibliográfica, pois ocorrem consultas a materiais já publicados, como livros e artigos científicos (SILVA e MENEZES, 2005). Além do estudo de caso que permite confrontar o estudo semelhantes e testar uma teoria. Este procedimento metodológico baseia-se na Pesquisa de Campo e na Pesquisa Documental. (GIL, 1994). O presente estudo de caso consiste na pesquisa de aplicações da logística reversa em um ambiente de serviços, mais especificamente na devolução de itens do ramo farmacêutico. Conforme já explicitado na introdução deste trabalho, objetiva analisar o fluxo do processo de devolução através da ótica da logística reversa e identificar oportunidades de melhoria. 


\subsection{AMBIENTE DE APLICAÇÃO}

A aplicação do estudo de caso ocorreu em uma multinacional de grande porte do mercado farmacêutico, com 5 mil colaboradores, é uma sólida plataforma industrial no país. Seu compromisso com o Brasil se verifica tanto pela produção local de $90 \%$ dos medicamentos em saúde humana que comercializa no país, quanto programa sustentado de investimentos, inclusive de pesquisa. No Brasil, o grupo francês é representado por cinco empresas que ocupam posições de liderança em seus segmentos de negócios. Em 2009, passou a deter $11,4 \%$ do mercado farmacêutico, ocupando a primeira posição considerando o market share. A busca incessante da empresa por excelência operacional e liderança de mercado, atrelados a preocupação de constantes desperdícios que chegam a ultrapassar 24 milhões de reais ao ano, motiva que haja uma atenção especial para um processo bastante significativo e presente na satisfação dos clientes quanto ao recebimento dos produtos: a devolução. Tratando-se por diversas vezes de itens perecíveis de alto valor agregado, é uma atenção maior, evitando não apenas a insatisfação do cliente quanto o constrangimento e prejuízo para a organização. A companhia conta com o apoio de uma equipe de 6 colaboradores, no qual trabalham exclusivamente com o processo de devolução de itens que apresentam divergências. Este processo pode ser classificado em duas categorias: Devolução no Ato e Devolução Após. As devoluções no ato, ocorrem em até 10 dias após a entrega da mercadoria. Já as devoluções após são mercadorias que são devolvidas após 10 dias da entrega. Para o presente estudo será restrito especificamente a devolução no ato devido a maiores oportunidades e melhorias ao nível de serviço ao cliente. Ademais, na cadeia de suprimentos o trabalho será feito entre CD da Indústria farmacêutica e atacado/varejo.

\subsection{DESCRIÇÃO DO PROCESSO}

A partir das visitas realizadas ao centro de distribuição atrelado as entrevistas com colaboradores chave, foi realizado o mapeamento macro do processo de devolução no ato descrito na Figura 1.

Figura 1 - Fluxograma do processo de devolução da empresa

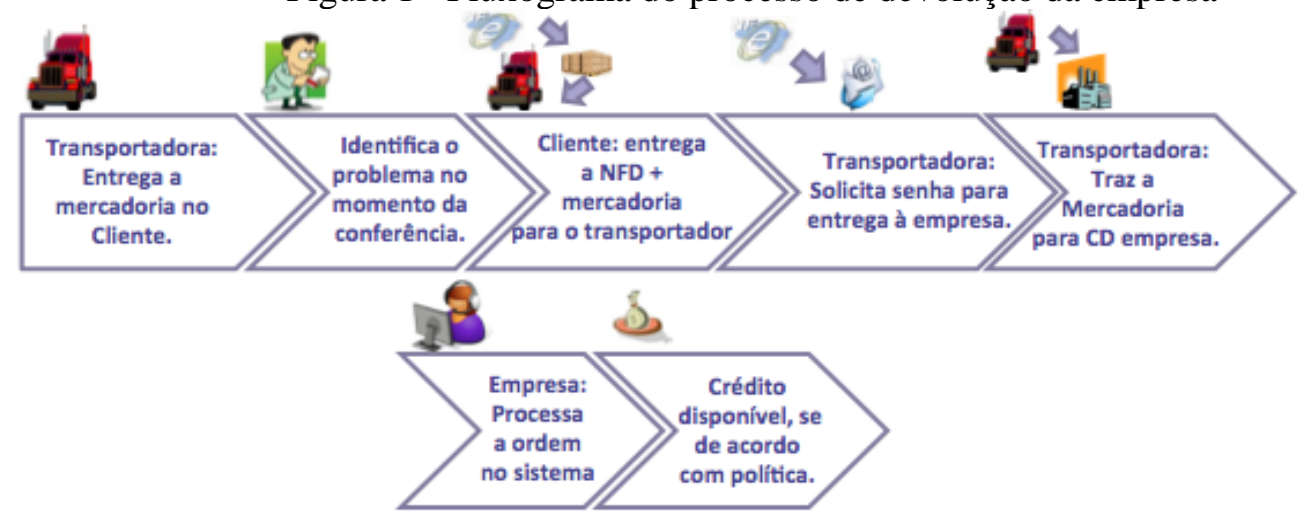

Fonte: Elaborado pelos autores 


\subsection{COLETA DE DADOS}

A coleta de dados foi dividida entre parte prática de visita técnica ao centro de distribuição e a parte administrativa. Nas visitas realizadas ao centro de distribuição houve a supervisão do líder para fornecer overview do processo e entrevistas dirigidas aos colaboradores com o objetivo de esclarecer e facilitar o entendimento do trabalho e etapas do processo. Para a avaliação do processo de LR, os principais dados a serem coletados são referente ao volume de devolução de medicamentos e seus respectivos motivos. Na coleta de dados administrativos foi necessária uma reunião com representantes da área de Customer Service, pertencentes à diretoria de Supply Chain, quais são responsáveis por toda tratativa de devolução e interface do cliente. Foi apresentado uma amostra de dados em valor líquido (forma mais representativa de perda de lucro pela empresa) onde continha as divergências usuais de devoluções no ato que a companhia obteve no período de Janeiro/2017 à Junho/2017, onde através do Microsoft Excel os dados foram devidamente trabalhados para que as oportunidades de melhorias fossem identificadas e devidamente analisadas.

\subsection{ANÁLISE DE DADOS}

Após a coleta de dados administrativos e a tabulação no Microsoft Excel, as informações foram organizadas com o intuito de extrair estritamente o necessário, apenas divergências na devolução ato. A metodologia para a organização, obedeceu a distribuição de Pareto, a qual agrupa e ordena a frequência de determinadas ocorrências. Isto que dizer que os motivos mais recorrentes são priorizados. Com a amostra de seis meses de ocorrências, foi possível organizar de forma decrescente de acordo com o montante de perda. Para isso, foi utilizado a ferramenta da qualidade Diagrama de Pareto com o objetivo de priorizar a resolução de motivos mais críticos pelos quais os clientes devolvem itens. Segundo Rodrigues (2004) esta ferramenta é um recurso gráfico utilizado para estabelecer uma ordenação nas causas de perdas que devem ser sanadas, auxiliando na identificação dos problemas, possibilitando a concentração de esforços para saná-las. A criação do gráfico de Pareto para este estudo permitiu ilustrar o cenário que a companhia enfrenta quanto a perda financeira de devolução, como também melhor visualização das divergências críticas no processo, que pode ser observado no Gráfico 1.

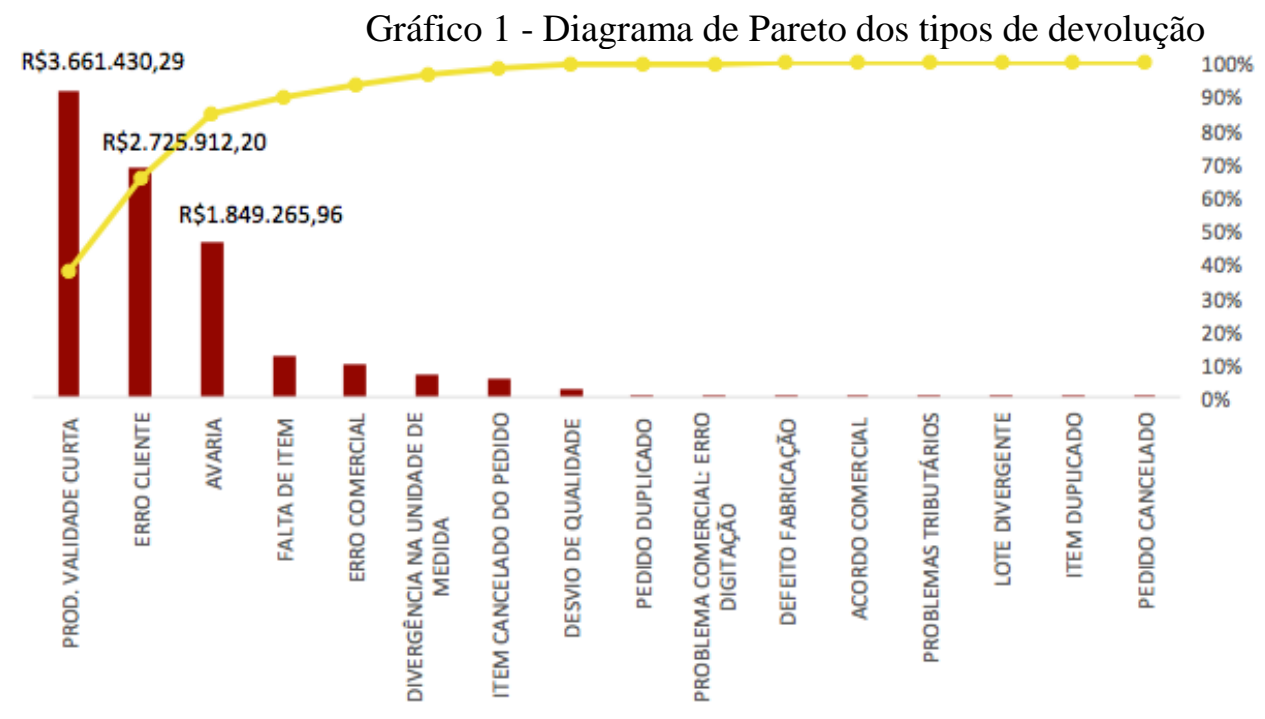


Fonte: Elaborado pelos autores

O Gráfico 1 apresenta 16 motivos de devolução, organizados de ordem decrescente no que tange volume $\mathrm{x}$ valor. Na primeira barra, representando mais de 3,6 Milhões, é destacado o produto com validade curta, ou seja, foi devolvido por sua validade estar próxima de vencimento. Em seguida, o motivo de devolução por erro de cliente ultrapassa 2,7 Milhões que é acompanhado por avaria no produto. Neste gráfico, os valores destacados são em unidade monetária ( $\mathrm{R}$ \$) Reais do Brasil que foram contabilizados como perda visto que, as devoluções são custeadas pela empresa estudada. Vale ressaltar ainda que, não foram evidenciados os valores referente à segunda entrega para suprir o retorno destas mercadorias devolvidas. A partir da análise do gráfico de Pareto foi constatada a existência de problemas relevantes e de oportunidades de melhorias. Como consequência do banco de dados, foram obtidos dezoito tipos de ocorrências, dentre elas apenas três representam $84 \%$ das perdas do processo. Se analisarmos financeiramente, o $80 \%$ do diagrama de Pareto reflete em mais de 8 milhões em seis meses para a empresa do ramo farmacêutico, enquanto todo o resto equivale a 1,5 milhão de reais. Assim, com base nas oportunidades de melhorias, sob a ótica da Logística Reversa, foi elaborado um plano de ações com intuito de reduzir os problemas, minimizando as consequências no processo. As ações a serem implementadas foram sugeridas com o objetivo de eliminação perdas no processo, que por si só indica um elevado custo. Destacando-se no primeiro lugar, mais representativo em perdas para a companhia, encontra-se o motivo de devolução do produto com validade curta, com a porcentagem de $37 \%$. Este motivo de devolução acontece quando no ato da entrega, o item está com validade abaixo do que está cadastrado no cliente. Representando $28 \%$, a segunda divergência é o erro do cliente. Este tipo de devolução ocorre quando o cliente envia pedido incorreto, seja o item, quantidade, desconto, preço. Nesse caso, no momento da entrega, a nota fiscal difere do pedido que consta no sistema do cliente. Por fim, acumulando $84 \%$ de criticidade, a avaria. Com quase $20 \%$ de importância nas perdas da empresa, a avaria trata-se de cargas com dano, qual pode ter sido causado pelo manuseio incorreto no carregamento, locomoção ou descarga da mercadoria. Por meio de estudos dos processos, usando ferramentas da qualidade, foram analisadas as causas dos problemas destacados e propostas algumas possíveis soluções para prevenção e correção de divergências como pode ser visualizado no Quadro 1.

\begin{tabular}{|c|c|c|}
\hline \multicolumn{3}{|c|}{ MOTIVO CAUSA } \\
\hline $\begin{array}{l}\text { Produto com } \\
\text { validade curta }\end{array}$ & $\begin{array}{l}\text { Item cadastrado no } \\
\text { sistema do cliente com } \\
\text { validade menor do que o } \\
\text { bloqueio de faturamento } \\
\text { da farmacêutica }\end{array}$ & $\begin{array}{l}\text { Atualização do cadastro do cliente para validade que a } \\
\text { empresa fornece; } \\
\text { Caso o cliente não aceite o recebimento abaixo da validade } \\
\text { cadastrada, todos os pedidos enviados passarão por uma } \\
\text { análise antes do faturamento conferindo sua validade, } \\
\text { providenciando o cancelamento antes do envio, caso não } \\
\text { esteja de acordo. }\end{array}$ \\
\hline $\begin{array}{l}\text { Erro } \\
\text { cliente }\end{array}$ & $\begin{array}{l}\text { Erro na emissão do } \\
\text { pedido }\end{array}$ & $\begin{array}{l}\text { Alinhamento quinzenal dos descontos e preços com o } \\
\text { cliente para atualização do pedido no sistema }\end{array}$ \\
\hline Avaria & $\begin{array}{l}\text { Manuseio incorreto, } \\
\text { transporte inadequado ou } \\
\text { empilhamento incorreto }\end{array}$ & $\begin{array}{l}\text { Utilização de cantoneiras para garantir a integridade das } \\
\text { caixas no transporte e armazenamento; } \\
\text { Avaliação dos pallets utilizados e obediência dos critérios } \\
\text { para empilhamento }\end{array}$ \\
\hline
\end{tabular}

Fonte: Elaborado pelos autores

No caso do primeiro motivo relacionado no Quadro 1, o motivo de chegar no 
cliente um lote de produtos com validade próxima do vencimento, é devido a algum erro no sistema ou atualização de informações. Tal erro não garante o bloqueio do faturamento, autorizando o envio da remessa. Como possível solução, foi sugerido uma atualização com mais frequência do cadastro (de clientes e de produtos), e elaboração de procedimento que garante a análise de todos os documentos pertinentes antes da emissão da nota fiscal. Para o segundo erro evidenciado, o erro na emissão do pedido, fica como sugestão a comunicação de modo efetivo entre os elos para minimizar erros inerentes à confirmação pedido. Por fim, no caso do terceiro erro identificado como relevante por meio do gráfico de Pareto, o motivo denominado avaria, resultado de manuseio incorreto ou transporte e armazenamento inadequado, foi avaliado com o mesmo critério. Assim, foi sugerida a utilização de cantoneiras para garantir a integridade das caixas no transporte e armazenamento. Além de obedecer as normas do setor, para o manuseio notou-se a necessidade de treinamento constante dos operadores de empilhadeira e demais funções para maior cautela em suas respectivas atividades.

\section{CONSIDERAÇÕES FINAIS}

Os objetivos propostos para o trabalho foram alcançados, sendo possível observar o fluxo de retorno dos itens da empresa pesquisada e os principais motivos de logística reversa na empresa estudada. Considerando que os materiais são devolvidos antes de serem consumidos, é possível caracterizar este fluxo reverso como sendo logística reversa de pósvenda. No caso do pós venda, é importante o monitoramento da entrega para garantir a conclusão da venda, que se dá após a validação do recebimento do produto e aceite do cliente. Apesar da satisfação do cliente estar associada muitas das vezes à qualidade do produto, a garantia da entrega do produto faz parte da satisfação, visto que a rapidez pode contribuir com a superação de expectativa do cliente. Ademais, a qualidade do transporte garante a integridade do produto, aumentando o grau de confiabilidade da marca. A flexibilidade do fornecedor de retornar um determinado pedido também apresenta ao cliente uma capacidade de resiliência apesar do elevado custo de retorno.

Baseada nessas informações, nos dados coletados e análise realizada, foi possível evidenciar três dos principais motivos nos quais acontece o processo de devolução no momento pós-venda: validade curta, erro no pedido do cliente e avaria. As soluções apresentadas indicam uma maneira de diminuir ou eliminar tais tipos de devolução. Vale ressaltar que as alternativas propostas são apenas sugestão para os gestores da empresa, visto que cabe a estes determinar as melhores estratégias a serem adotadas. A primeira solução encontrada pode solucionar com o motivo de devolução de validade vencida, uma vez que a atualização da informação no sistema torna a relação com o cliente mais aberta, podendo em curto prazo ganhar sua fidelização. Já a segunda solução proposta para o problema de erro no pedido traz uma dinâmica melhor ao sistema, trazendo mais ferramentas ao cliente no momento de fazer um pedido. A última solução para o problema de avaria é um processo mais lento para lento para sua boa eficiência e demanda testes e possíveis ajustes até que esse problema seja totalmente resolvido. Portanto, o trabalho em questão demandou estudar a logística reversa dos medicamentos no momento que o cliente faz a devolução do pedido e um estudo mais profundo das causas deste problema. Utilizando ferramentas da qualidade como o Diagrama de Pareto para identificar os motivos das devoluções, foi possível analisar o processo logístico reverso como um todo e apresentar possíveis soluções para que essas ocorrências diminuam. Sugere-se também, abordagens complementares sobre o tema buscando discutir demais esferas que o assunto se enquadra (OLIVEIRA e GONÇALVES, 
2016) tentando identificar características técnicas (GONÇALVES et al, 2019) e buscando utilizar métodos disponíveis na literatura para otimizar a rede reversa deste resíduo (FERRI et al, 2017).

\section{REFERÊNCIAS BIBLIOGRÁFICAS}

[1] Agência Nacional de Vigilância Sanitária- ANVISA. Manual de Gerenciamento de Resíduos. Disponível em: Acesso em: 23 mar. 2019.

[2] Associação Brasileira de Normas Técnicas - ABNT. Combate aos desafios ambientais com a ISO 14000. Disponível em: Acesso em: 17 abr. 2019.

[3] BRASIL. Decreto-lei no 12.305, de 02 de Agosto de 2010. Institui a Política Nacional dos Resíduos Sólidos.,

[4] Disponível em: Acesso em: 21 out. 2018.

[5] Companhia Ambiental do Estado de São Paulo - CETESB. Logística Reversa no Estado de São Paulo. Disponível em: Acesso em: 2 dez. 2018

[6] Conselho Regional de Farmácia do Estado de São Paulo - CRFSP. Resíduos e Gestão Ambiental. Jul de 2012. Disponível em: < http://portal.crfsp.org.br/component/content/article/268-revista-107/3803-residuosegestao-ambiental.html>. Acesso em: 21 out. 2018

[7] DE BRITO, M. P. Managing reverse logistics or reversing logistics management. Tese de Doutorado. Erasmus University Rotterdam, Rotterdam, 2003.

[8] DE BRITO, M. P.; DEKKER, R. Reverse logistics: a framework. Econometric Institute. Report EI 2002-38, Erasmus University Rotterdam, The Netherlands, 2002.

[9] Escola Politécnica da Universidade de São Paulo. Acordos setoriais para implantar logística reversa em coletas de resíduos avançam no Brasil. Disponível em: Acesso em: 2 set. 2018.

[10] FERRI, Giovane Lopes; MATAVEL, Nilza Isabel; GONÇALVES, Max Filipe Silva; RIBEIRO, Glaydston Mattos; Gisele de Lorena Diniz, Models for localizing facilities in solid waste management: a bibliometric review. Brazilian Journal of Production Engineering. São Mateus, Vol. 3, N. ${ }^{\circ}$ 2, p. 40-56. (2017).

[11] GARCIA, Manuel. Logística reversa: uma alternativa para reduzir custos e criar valor. Disponível em: < http://cplsolucoes.com.br/2015/wpcontent/uploads/2015logistica_reversa_manuel_garc ia.pdf > Acesso em: 12 set. 2018.

[12] GIL, Eric de Souza. GARROTE, Clévia Ferreira Duarte. DA CONCEIÇÃO, Edemilson Cardoso. SANTIAGO, Mariangela Fontes. DE SOUZA, Aparecido Ribeiro. Aspectos técnicos e legais do gerenciamento de resíduos químicofarmacêuticos. Disponível em: Acesso em: 17 out. 2018.

[13] GONÇALVES, M. F. S.; PEREIRA, N. C. ; TERENCE, M. C. . Application of Reverse Logistics for the Recycling of Polypropylene Waste and Oyster Shell. DEFECT AND DIFFUSION FORUM, v. 391, p. 101, 2019. 
[14] Ministério do Meio Ambiente - MMA. Política Nacional de Resíduos Sólidos: Contexto e principais aspectos. Disponível em: Acesso em: 2 set. 2018.

[15] OLIVEIRA, Mariana Matos; GONÇALVES, Max Filipe Silva. Perspectivas do óleo residual de fritura: uma abordagem econômica, jurídica e socioambiental. Revista Espacios. Vol. 37. N. 25. P. 17. 2016.

[16] RODRIGUES, Marcus Vinicius. Ações para qualidade: GEIQ, gestão integrada para a qualidade: padrão seis sigma, classe mundial. Rio de Janeiro: Qualitymark, 2004.

[17] SILVA, Carlos. CARVALHO, Diogo. A importância da Logística Reversa e o estudo de caso da indústria do alumínio. Disponível em: < http://lfcompiani.dominiotemporario.com/doc/logistica_reversa_aluminio.pdf> Acesso em: 12 set. 2018.

[18] Sistema Nacional de Informações Sobre a Gestão dos Resíduos Sólidos - SINIR. Logística Reversa. Disponível em: Acesso em: 2 set. 2017.

[19] YIN, Roberto K. Estudo de caso: planejamento e métodos. $2^{a}$ edição. Bookman, 2001

[20] YTOSHI, Fábio. GIRO, Roberto. SANTOS, Roberto. A Logística Reversa e a sustentabilidade empresarial. Disponível em: < http://webresol.org/textos/a_logistica_reversa_e_a_sustentabilidade_empresarial.pdf > Acesso em: 13 set. 2018. 